\title{
(S)ELECCIÓN EN ESTABLECIMIENTOS POLIVALENTES: CUANDO LAS CALIFICACIONES CONDICIONAN LAS ELECCIONES EDUCATIVAS ${ }^{1}$
}

\author{
María-Paola Sevilla², \\ Leandro Sepúlveda ${ }^{3}$
}

\begin{abstract}
RESUMEN
En Chile, los establecimientos educacionales que imparten tanto enseñanza media humanista-científica (HC) como técnico-profesional (TP) son conocidos como polivalentes. Este artículo describe las dinámicas escolares al interior de un establecimiento polivalente que utiliza las calificaciones escolares como criterio principal de conformación de cursos de formación general y posterior distribución de estudiantes entre las modalidades HC y TP. La descripción se realiza a partir de los antecedentes recabados en un estudio con enfoque etnográfico en un establecimiento de la Región Metropolitana de Santiago de Chile. Los hallazgos muestran los efectos adversos asociados al ordenamiento por calificaciones para la asignación de las modalidades formativas, ya que se produce una circularidad viciosa al estigmatizar al alumnado según su curso de procedencia. Asimismo, la elección condicionada por calificaciones canalizaría a los estudiantes mejor evaluados hacia la modalidad $\mathrm{HC}$, mientras que provocaría situaciones de reasignación pasiva o desajuste vocacional en quienes se incorporan a la modalidad TP. Con este procedimiento se replicaría la segmentación según tipo de modalidad de estudios que caracteriza al sistema escolar chileno, desaprovechándose la oportunidad de un modelo polivalente para brindar alternativas curriculares igualmente valoradas por los estudiantes y canalizar de forma oportuna sus intereses vocacionales.
\end{abstract}

Conceptos clave: educación técnico-profesional, selección educativa, elección educativa, etnografía, discursos docentes.

\section{(S)ELECTION IN POLIVALENTES SCHOOLS: WHEN SCHOOL GRADES AFFECT EDUCATIONAL CHOICES}

ABSTRACT

In Chile, high schools that offer both university preparation and vocational education are called "polivalentes". This article describes the school dynamics within a polivalente school that uses grades as the main criterion to group students into different classes at the lower secondary

1 Este artículo es parte del proyecto "Selección en liceos polivalentes. Análisis de los mecanismos de adscripción de estudiantes a la modalidad científico-humanista o técnicoprofesional" financiado por el Ministerio de Educación de Chile a través del Fonide F711296.

2 Universidad Alberto Hurtado, Facultad de Educación. Santiago, Chile. Contacto: msevilla@ uahurtado.cl

3 Universidad Alberto Hurtado, Facultad de Educación. Santiago, Chile. Contacto: lesepulv@ uahurtado.cl 
level, as well as to sort students between university prep and vocational education, at the upper secondary level. We use data from a single case study with an ethnographic approach conducted in a polivalente school located in the Metropolitan Region of Santiago, Chile. The findings show the adverse effects of student tracking, as it generates a vicious cycle by stigmatizing students according to their assigned group. Furthermore, the decision to track students based on their grades creates a scenario where those with the top grades are guided towards university prep, while possibly causing a passive reassignment or vocational mismatch for those assigned to the vocational track. This practice replicates the segmentation by education modality, that characterizes the Chilean secondary school system and does not take advantage of the polyvalent model's potential to offer educational alternatives that are equally valued by the students and to channel their vocational interests, in a timely manner.

Key concepts: educational choices, ethnography, teacher discourses, vocational education.

\section{Introducción}

Más allá de las modificaciones introducidas recientemente por las políticas de inclusión educativa, la participación y decisión de las familias es un supuesto que está en las bases del modelo educativo chileno. En general, dentro de restricciones socioeconómicas evidentes, se elige no solo el establecimiento educativo al que asisten los estudiantes, sino también la modalidad de estudios que estos cursarán en la enseñanza media, ya sea humanista-científico (HC) o técnico-profesional (TP) y, al interior de esta última, una especialidad asociada a un sector económico en particular. En efecto, la opción por modalidad de formación en la enseñanza media, a menudo determinada por razones económicas y que tiene que ver con la pertenencia a una clase social definida, ha sido planteada desde sus inicios en términos de una elección familiar o la expresión de preferencias estrictamente individuales (Ruiz, 2010). De ese modo, el sistema educativo chileno se ha diferenciado de otros modelos — como el alemán o el japonés_, que también ofrecen un currículum diferenciado en el nivel secundario, pero donde los estudiantes son separados en distintas opciones formativas fundamentalmente en función de sus calificaciones previas, o según resultados logrados en exámenes competitivos (Bracey, 2001).

La evidencia empírica en Chile relativa a la elección del tipo de educación media, si bien no es tan extensa como la evidencia 
disponible acerca de la elección de establecimientos, arroja luces importantes en torno a este tema. La elección entre educación HC y TP, por sobre los intereses vocacionales y aspiraciones futuras de los estudiantes, estaría influida fuertemente por el medio y el entorno familiar, replicándose en ella las diferencias de origen del alumnado. Así lo muestran algunos trabajos que estudian esta elección educativa al término de la enseñanza básica, cuando ocurre en conjunto con la elección de establecimiento de enseñanza media especializado (sea este HC o TP) (Farías, 2011; Raczynski y Hernández, 2011). Esta influencia del nivel socioeconómico también se reproduciría a nivel de los establecimientos polivalentes que imparten ambos tipos de educación, cuando sus estudiantes a partir del grado 11 (tercer año medio) son separados en distintos cursos según tipo de currículo cursado. Esto aun cuando los establecimientos tendrían la posibilidad de propiciar decisiones más informadas en sus estudiantes, privilegiando sus intereses vocacionales por sobre su condición de origen, toda vez que la elección de modalidad formativa ocurre más tarde (Sevilla y Sepúlveda, 2016). Además, sucedería que, en un grupo de establecimientos polivalentes, las recomendaciones de docentes o la imposición de requisitos de adscripción a las distintas opciones curriculares impartidas, condicionarían las elecciones de los estudiantes más allá de constricciones socioeconómicas (Sevilla, 2016).

El objetivo de este artículo es describir las dinámicas escolares que se producen en un establecimiento polivalente que utiliza como criterio de conformación de cursos HC y TP las calificaciones escolares, condicionando las elecciones educacionales de sus estudiantes. Para ello, se analizan las creencias y discursos de directivos y docentes que apuntan a hacer legítima esta práctica, junto con las percepciones de los estudiantes que son afectados por la misma. El estudio, que sigue un enfoque etnográfico, al proponerse mostrar los hechos tal como suceden y contrastar las prácticas con los discursos de los actores involucrados (Wilcox, 1988), se realiza en un establecimiento polivalente particular pagado de la Región Metropolitana de Chile que imparte, junto a la modalidad HC, especialidades TP del sector de administración y comercio. Se quiere aportar a la discusión acerca de los efectos adversos del tracking escolar, término con el 
cual la literatura anglosajona refiere a la práctica de ordenar a los estudiantes de un mismo grado en distintos grupos de instrucción según rendimiento académico previo (Oakes, 1985), y cuyo potencial teórico ha sido escasamente explotado por la investigación nacional. El establecimiento elegido para ilustrar las dinámicas que genera la práctica del tracking en los cursos de formación diferenciada (grados 11 y 12), también utiliza las calificaciones escolares para conformar los cursos de formación general (grados 9 y 10), lo que constituiría una práctica más que frecuente en la educación media chilena para el manejo de la heterogeneidad de estudiantes según estudios recientes (Treviño et al., 2018).

El artículo se organiza en cinco secciones incluida esta introducción. La segunda sección contiene una breve revisión de la literatura sobre el tracking escolar y sus efectos en la eficiencia y equidad educativa. La tercera sección entrega elementos de contexto y presenta al establecimiento polivalente Almirante Barroso ${ }^{4}$, junto con especificar a los informantes e instancias de levantamiento de información en esta institución escolar. La cuarta sección contiene los hallazgos del estudio con enfoque etnográfico; y finalmente, la quinta sección está destinada a la discusión final del trabajo.

\section{Propósito y consecuencias del tracking escolar}

En principio, el objetivo fundamental del tracking escolar es adaptar la oferta educativa a los intereses y necesidades de los estudiantes, haciendo más eficiente el proceso formativo y favoreciendo el desarrollo de aprendizajes. Teóricamente, la eficiencia se alcanza cuando los estudiantes agrupados con pares de similares capacidades o niveles previos de logro aprenden más, ya que las estrategias de instrucción se vincularían estrechamente con el nivel de sus habilidades. El tracking reduciría el fracaso escolar, al mismo tiempo que ayudaría a mantener el interés de los estudiantes aventajados, quienes no se aburrirían con la participación de otros más atrasados académicamente (Ansalone, 2009; Collins \& Gan, 2013). No

Nombre de fantasía con el cual se refiere al establecimiento sujeto de estudio en esta investigación. 
obstante, al tracking también se le atribuyen costos que se asocian con las menores oportunidades que tendrían los estudiantes rezagados, principalmente porque no se benefician del efecto par, al estar con otros de mayor rendimiento y ser estigmatizados por el resto de sus pares. Asimismo, se argumenta que, para estos grupos de menor rendimiento, los docentes reducirían sus expectativas y se produciría una diferenciación y polarización del currículo. Además, dado que los resultados educacionales están asociados a factores tales como el nivel socioeconómico o la condición étnica de los estudiantes, el tracking discriminaría negativamente a ciertos grupos, convirtiéndose en un mecanismo de reproducción de desigualdades (Lucas \& Berends, 2002).

En general, son dos las orientaciones que se confrontan en los estudios empíricos del tracking escolar: una de corte funcionalista, que valora la práctica en la medida en que permite a las escuelas ser más eficientes en términos de su productividad promedio y una de tipo social, que la juzga por sus repercusiones sociales, en especial, por su impacto en la equidad (Loveless, 1999). Bajo el lente de estas perspectivas, el tracking es visto como una acción de equilibrio compensatorio o trade off entre eficiencia e igualdad de oportunidades. Con todo, ayudaría a resolver la tensión entre las funciones de adaptación e integración que los sistemas educativos están llamados a cumplir. La primera función requiere que las escuelas produzcan excelencia académica, por lo que necesitan ser selectivas y mantener altas exigencias curriculares. Por su parte, la función de integración les demanda proveer educación a todos sin distinción. El tracking eliminaría el dilema, al delegar a los tracks selectivos la función de adaptación, mientras que los tracks inferiores serían los encargados de ofrecer educación a las "masas" (Clark, 1962, citado por Shavit, 1984).

En su acepción más pura el tracking de estudiantes se realiza básicamente en función de criterios académicos como las notas, los puntajes en pruebas estandarizadas o los test de habilidades. Sin embargo, en la práctica son considerados también otros factores, tales como intereses y proyecciones de los estudiantes, recursos docentes y curriculares del establecimiento, entre otros. La inclusión 
de estos criterios no académicos redunda en grupos de instrucción más heterogéneos en términos de habilidades, pudiéndose encontrar estudiantes de similares niveles de destreza en tracks adyacentes. La extensión en la que estos factores son incluidos y ponderados con los académicos varía entre sistemas escolares y al interior de ellos, por lo que la ubicación de un estudiante en un determinado track de enseñanza depende en gran parte de las características organizacionales del establecimiento al que asista (Hallinan, 1994).

Se argumenta también que la implementación de diferentes tipos de currículo en la educación secundaria — concordantes con los intereses o aspiraciones de los jóvenes- es una forma de tracking, en la medida en que reduce la variación de conocimientos o habilidades que la escuela intenta transmitir en un período determinado de tiempo. Distintos autores coinciden con esta posición (Ainsworth \& Roscigno, 2005; Gamoran, 1992) demostrando que en los procesos de agrupamiento de estudiantes, aún sin requisitos académicos formales para optar a uno u otro currículo, el tracking operaría a través de la influencia que ejercen las opiniones de los docentes y pares en sus decisiones, en particular, a través de sus recomendaciones. En contraposición con estos autores, Lucas y Berends (2002) señalan que la diferenciación curricular es una condición necesaria, pero no suficiente para la existencia de la práctica del tracking. Según la definición que estos autores emplean en su análisis, el tracking existe solo cuando hay una asociación en el tiempo entre los niveles académicos de los estudiantes y los grupos en los que se ubican, ya sea en el ámbito de sala de clases o de la unidad educativa. Cuando esto ocurre, sin que exista en la escuela un procedimiento formal de separación de estudiantes en distintos grupos, se habla de factotracking o separación de hecho, que difiere del tracking oficial, que está mediado por procedimientos formales y públicamente conocidos por los actores escolares.

A pesar de las distintas formas que el tracking pueda tomar en las instituciones escolares, esta práctica tiene rasgos comunes que permiten identificar su despliegue y predecir sus consecuencias (Oakes, 1985). Estas características son: a) el enjuiciamiento que se realiza al desempeño intelectual del estudiante para determinar 
el grupo curso en el que será ubicado; b) la denominación o etiquetamiento de los distintos grupos según el nivel de desempeño de los estudiantes o su destino postsecundario; c) la adaptación del currículum e instrucción de cada track a las necesidades y habilidades percibidas de los estudiantes asignados a ellos; d) la constitución de grupos no comparables, sino más bien jerarquizados, donde uno de estos se ubica en el nivel más alto y privilegiado, y finalmente e) las distintas experiencias escolares que experimentan los estudiantes según el track o grupo cursos al cual fueron asignados. Es por este conjunto de atributos estructurales que el tracking no es una práctica organizacional neutra meramente técnica, sino que está asociada a los valores y creencias de las instituciones o sistemas en donde se implementa. Por lo tanto, sus consecuencias no solo deben ser juzgadas en términos de avances cognitivos de los estudiantes, sino que también se deben considerar los efectos sociales y culturales que genera en su entorno (Oakes y Guiton, 1995).

La forma en que se verifica la práctica del tracking en el sistema educativo en Chile, y muy particularmente en los establecimientos polivalentes, merece desde esta perspectiva una mayor consideración de la que hasta ahora ha tenido en la investigación socioeducativa. Como se ha podido identificar en estudios recientes (Sevilla y Sepúlveda, 2016), en establecimientos polivalentes del sector municipal, la modalidad TP emergería como la alternativa más atractiva, al visualizarse débiles proyecciones de acceso a la educación superior en los estudiantes, considerando el contexto de vulnerabilidad que enfrentan la mayoría de ellos. En cambio, en contextos más favorecidos socioeconómicamente, y donde los establecimientos particulares subvencionados tienen mayor presencia, la modalidad HC aparece como la más valorada, y se tienden a desplegar mecanismos de regulación de cupos poco inclusivos y académicamente selectivos cuando estos se basan en las calificaciones previas de los estudiantes. Así, la elección de modalidad de estudios en la educación media, basada fundamentalmente en las preferencias el alumnado, quedaría en entredicho en estos espacios escolares, surgiendo la interrogante acerca del tipo de creencias y discursos que justifican los procedimientos definidos y que pueden magnificar la segmentación entre las modalidades HC y TP, más allá 
de lo que ocurre en el sistema educativo en su conjunto. Este es el principal eje de interés del presente trabajo.

\section{Antecedentes del caso de estudio}

\subsection{Contexto}

En Chile, el surgimiento y consolidación de los establecimientos polivalentes se debe fundamentalmente a una decisión de tipo pragmática. Aunque existen algunas experiencias previas acotadas y que fueron descontinuadas en el tiempo, el principal impulso al modelo polivalente está asociado a la implementación del "Programa de habilitación de establecimientos HC con especialidades técnicoprofesionales" de los años 1992 y 1993, en el contexto de la masificación de la educación media. El programa buscó expandir la modalidad TP en sectores urbanos y rurales marginales, bajo la convicción de que una formación laboral en la enseñanza media permitiría más fácilmente la inserción en el mercado del trabajo de los jóvenes egresados de este nivel, que no tuvieran posibilidades inmediatas de continuar estudios superiores. Para las autoridades de la época, no se justificaba la creación de nuevos liceos TP si ya existían liceos con formación HC interesados en diversificar su oferta educativa y con una infraestructura en condiciones de ser mejorada y equipada con talleres de alguna de las especialidades TP. Como resultado de este diagnóstico, se reconvirtieron 87 liceos del sector municipal en establecimientos polivalentes promoviéndose así, de manera indirecta, este modelo de provisión educativa al interior de la educación media a nivel nacional (Bobenrieth y Cáceres, 1994; Cariola, 2003).

Son también pragmáticas las decisiones que se asocian a la lógica de mercado que ha imperado en el sistema educativo chileno en las últimas décadas, lo que ha llevado a que algunos sostenedores de establecimientos particulares subvencionados especializados en educación HC o TP diversificaran su oferta formativa, acoplando la otra modalidad educativa como una estrategia de captación de mayor matrícula. Como resultado, aún después del término del "Programa de habilitación de establecimientos HC”, el número de liceos polivalentes 
ha seguido en aumento hasta el presente; principalmente, porque establecimientos particulares subvencionados TP, en respuesta a las nuevas demandas y necesidades de los estudiantes con expectativas de ingreso a la educación superior, han sumado la HC a su oferta formativa (Sevilla y Sepúlveda, 2016).

En el año 2017 los establecimientos de tipo polivalente ascendieron a 354 unidades educativas, albergando alrededor del $20 \%$ de la matrícula de enseñanza media. De este total, el 62\% son de dependencia municipal y el restante 38\% de dependencia particular subvencionada. Los primeros matriculan a una población escolar de bajo nivel socioeconómico, mientras que los segundos suelen ubicarse en entornos sociales emergentes y, por lo tanto, congregan a estudiantes de familias de mayor heterogeneidad socioeconómica. En ambos grupos de establecimientos, la diversidad de especialidades técnicas es acotada y menor a la ofertada en establecimientos TP exclusivos circunscribiéndose, en un porcentaje importante, a especialidades del sector de administración y comercio.

\subsection{El establecimiento objeto de indagación}

El liceo polivalente Almirante Barroso, ubicado en la comuna de Santiago Centro, es un establecimiento particular subvencionado de educación media que se adscribió al sistema de financiamiento compartido vigente hasta la reforma del año 2016. Aunque en sus orígenes fue un establecimiento exclusivamente TP que impartía especialidades del sector de Administración y Comercio, desde el año 2000 sumó a su oferta educativa la opción HC, incorporando así a los estudiantes con expectativas de acceso a la educación superior universitaria, tal como lo refirió el director de este centro educacional en las entrevistas realizadas con antelación al trabajo de campo.

La matrícula del establecimiento, cercana a los 900 estudiantes, se distribuye en 24 cursos, seis por cada nivel educativo. Los cursos de los grados 9 y 10 de formación general asisten en el turno de la mañana, mientras que en el turno de la tarde concurren los estudiantes de los grados 11 y 12 de formación diferenciada. En estos niveles, al momento de la realización del trabajo de campo, 
dos cursos correspondían a la modalidad HC, mientras que la modalidad TP se organizaba en tres cursos de la especialidad de Administración, dos cursos de la especialidad de Contabilidad y un curso de la especialidad de Secretariado que, como ocurría en todo el país, presentaba una concentración fundamentalmente de estudiantes mujeres ${ }^{5}$. Aunque desigualmente distribuido en los grupos curso, en este establecimiento el número de estudiantes mujeres era levemente superior al de los varones (51\% y 49\%, respectivamente). Según datos del Sistema Nacional de Asignación con Equidad para Becas, Sinae, de la Junta Nacional de Auxilio Escolar y Becas, Junaeb, el indice de vulnerabilidad social y educativa del establecimiento se situaba alrededor del 38\%, correspondiendo al grupo de nivel socioeconómico medio según la clasificación de la Agencia de Calidad de la Educación, ACE.

Respecto de sus resultados académicos, el liceo obtuvo puntajes similares al promedio nacional de establecimientos de similar grupo socioeconómico en Comprensión Lectora y Matemática, de acuerdo con los resultados del Simce para el grado 10. En cambio, en la Prueba de Selección Universitaria (PSU) los resultados han sido menos alentadores, ya que en el último proceso de admisión el liceo en su modalidad HC ocupó la posición número 23 de un total de 32 liceos particulares subvencionados de la comuna de Santiago, mientras que en su modalidad TP, su posición fue la octava de un total de 10 centros educativos.

En cuanto a la planta docente del liceo, esta se compone de 28 docentes de aula, cuatro de los cuales son profesionales del área de administración y comercio. A ellos se suman cinco directivos y un orientador quien, al momento del levantamiento de la información, recientemente había organizado el Departamento de Orientación del establecimiento, con el objetivo de formalizar el proceso de postulación de los estudiantes a las distintas opciones curriculares impartidas y apoyarlos en sus decisiones vocacionales futuras.

La especialidad de Secretariado fue descontinuada luego de la reforma curricular del año 2015, finalizando la provisión de esta oferta formativa en la EMTP en el año 2017. 


\subsection{Consideraciones metodológicas}

El estudio de caso en el que se basa este artículo sigue un enfoque etnográfico en la medida en que pretende mostrar los hechos tal como acontecen. La etnografía es un método de investigación social que incluye una variedad de fuentes de información, y que se caracteriza principalmente porque quienes investigan participan de la vida cotidiana de quienes son investigados durante un tiempo relativamente extenso. Se trata de observar lo que sucede, escuchar lo que se dice, preguntando cosas que arrojen luz acerca del tema que se ha decidido estudiar (Hammersley y Atkinson, 1994). Sin embargo, la perspectiva etnográfica implica también un proceso analítico de carácter comprensivo con la perspectiva de alcanzar algún tipo de conocimiento, lo que delimita su intencionalidad y la distingue como estrategia investigativa (Wolcott, 2006).

Los estudios etnográficos en el ámbito escolar, si bien tienen una larga tradición abordando cuestiones significativas para el debate educacional, son estudios que tienen características particulares. Esto se debe principalmente a que las escuelas son instituciones burocráticas y esa condición constituye un obstáculo relevante para el desarrollo de intervenciones etnográficas en su interior (Díaz de Rada, 2008). Se trata de espacios jerarquizados, donde prevalecen principios de equivalencia funcional (los docentes o los estudiantes como actores estandarizados) y donde la disciplina y la norma institucional tienden a ocultar la diversidad y heterogeneidad de las expresiones en su interior. Este fue un punto relevante del estudio de caso que se presenta en este artículo, al estar el foco de interés investigativo en una experiencia donde las lógicas de acción jerárquica juegan un rol preponderante.

En consonancia con la orientación etnográfica seguida, el trabajo de campo que dio origen al material del estudio de caso se extendió por tres meses. En dicho período se realizaron visitas al establecimiento Almirante Barroso que coincidieron con el proceso de postulación de estudiantes del grado 10 a las opciones HC o TP impartidas en el ciclo de formación diferenciada (grados 11 y 12). El orientador del establecimiento fue el informante clave, permitiendo el acceso a actividades escolares y la realización de entrevistas con 
diversos actores de la comunidad educativa. Este profesional, junto con explicar en detalle las distintas fases de postulación de los estudiantes a las opciones de formación diferenciada impartidas en el liceo, hizo entrega de documentación relacionada con este proceso, como el informativo de orientación dirigido a los estudiantes y sus familias y el reporte de resultados de la encuesta de preferencias educacionales. Durante las visitas realizadas fue posible entrevistar en varias oportunidades a los integrantes del equipo directivo del establecimiento, y a los docentes y estudiantes vinculados con el proceso de conformación de cursos de formación diferenciada. Asimismo, se realizó observación participante en actividades asociadas a la postulación a los cursos HC y TP. En lo que sigue, se presentan los principales resultados de las indagaciones realizadas y sus consecuencias analíticas para la discusión en torno a la práctica del tracking escolar que acontece en los establecimientos polivalentes del sistema educativo chileno.

\section{Hallazgos del estudio}

\subsection{La diversidad que trae la polivalencia}

El liceo polivalente Almirante Barroso recibe cada año alrededor de 300 estudiantes que se incorporan a algunos de los cursos del grado 9. Desde que se amplió a HC y ofrece las dos modalidades educativas de enseñanza media, es más "diverso" y por ello más "exitoso", ya que sus cupos están casi siempre llenos. En el discurso predominante de sus actores educativos, y muy particularmente del equipo directivo, la polivalencia es leída en este establecimiento como una estrategia acertada de captación de mayor matrícula y, por lo mismo, de sustentabilidad del proyecto educativo en términos de su viabilidad económica:

Yo creo que en la diversidad está el éxito... es bueno ser polivalente (...) hay diversos intereses. Entonces si nosotros queremos tener el colegio completo como lo solicita el dueño del establecimiento, tenemos que tener diversidad, y aquí hay de todo, alumnos que quieren estudiar Administración, alumnos fascinados con Contabilidad y otros con HC (...). Aquí hablo 
de éxito en el sentido que me pide el dueño: mantener el liceo con una dotación de alumnos completa, en ese sentido te digo (Director establecimiento).

Ahora bien, el éxito que se alcanza a través de una mayor apertura curricular también tiene costos a juicio de los actores entrevistados. Primero, porque la diversidad que aporta la polivalencia traería complicaciones en la gestión del establecimiento admitiéndose que "un colegio se desempeña mejor en una sola área". Segundo, porque la diversidad se asociaría a la llegada de estudiantes muy distintos "con ganas y sin ganas de estudiar" y estudiantes "con buena y mala conducta, que no dejan enseñar adecuadamente al profesor", por lo que habría complicaciones de tipo socioeducativas que no siempre son adecuadamente ponderadas al momento de optar por una oferta curricular variada.

Llama la atención la escasa consideración de la polivalencia como un aporte al proyecto educativo del establecimiento al posibilitar el despliegue de una propuesta formativa que responda a los distintos intereses y proyectos de futuro de los propios estudiantes. En vez de ello, la diversidad que trae la polivalencia necesita ser controlada a través de un ajuste, el que se intenta alcanzar, como se verá a continuación, a través de la conformación de grupos curso según las calificaciones escolares.

\subsection{El ordenamiento por calificaciones en el ciclo de formación general}

Nosotros formamos cursos determinados seleccionando por notas. Necesitamos 40 alumnos para el $1^{\circ}$ año medio A y cortamos, cortamos para el B, etc. Por lo tanto, el primero A tiene promedio de 6,9 a 6,5. El primero B tiene promedio de 6,4 a 6,3, el primero $\mathrm{C}$ de 6,2 a 6,0. Entonces tenemos un primero $\mathrm{F}$ por allá que tiene promedios de 5,2 a 4,5 (Director establecimiento).

Según la descripción que realiza el director del establecimiento, la organización de cursos en el ciclo de formación general es una gradiente perfecta de notas, según se avanza en las letras del alfabeto en cada uno de los niveles de este establecimiento. Esta práctica de 
organización de grupos curso, conocida en la literatura anglosajona como tracking escolar, sería inevitable y justificable para enfrentar la diversidad y rescatar a quienes los docentes y directivos consideran buenos estudiantes. "Y no podemos nosotros no seleccionar, porque si no, ¿qué pasa con los alumnos que son buenos, y que tienen buena base? Salen perdiendo, porque bajan de nivel en todo", manifestó en una conversación uno de los docentes. El mecanismo de configuración de grupos curso homogéneos y diferenciados por resultados académicos, representa así una práctica institucionalizada y asumida por el conjunto de la comunidad docente, aunque se reconocen ciertos inconvenientes en su implementación:

Tú vas a trabajar a un $1^{\circ}$ o $2^{\circ}$ año medio A o B, y es una maravilla; tienes casi el 100\% de los alumnos concentrados, trabajando, si les pides una tarea, el 95\% la hace y el 5\% te pide disculpas y después la hace; eso es positivo. Sin embargo, en otros cursos la cosa es más complicada, y hasta cierto punto uno pierde la fe en algunos alumnos, al decir "esas notas tienen". Pero hay una historia detrás de eso, ya que de repente un alumno puede llegar de un colegio con un 6 , pero ese 6 está inflado y no es real, y a la inversa también. Entonces de repente lo podrían asignar a un curso $\mathrm{C}$ o $\mathrm{D}$, pero este alumno podría ser bastante mejor. Eso es una parte... no me convence digamos (Docente formación general).

No obstante, como se observa en esta cita, estos inconvenientes se asocian con la asignación errónea de alumnos a sus respectivos cursos. En general, no se identificó en las distintas conversaciones que se sostuvieron con los directivos y docentes del establecimiento una reflexión crítica acerca de los efectos adversos de la práctica del tracking escolar, como es el ajuste de expectativas respecto del desempeño de los estudiantes en función del curso de pertenencia. Se trata de grupos curso no comparables, en los que se produce una adaptación temprana a las exigencias y a la profundidad del currículo impartido en ellos. De ese modo, la pertenencia a un curso específico en $1^{\circ}$ y $2^{\circ}$ año medio influiría fuertemente en la posibilidad de elección de la modalidad HC o una especialidad TP. Así lo evidencian los siguientes relatos de docentes respecto de sus prácticas en las salas de clases: 
Yo veo que en $1^{\circ}$ y $2^{\circ}$ año medio se parte con el mismo plan para todos, pero las características de cada curso son como de familias distintas, una del campo y otra de la ciudad... Entonces empezamos a ver, $1^{\circ} \mathrm{A}$ y $1^{\circ} \mathrm{B}$ están rindiendo, podemos sacar más, podemos ir más allá; $1^{\circ} \mathrm{G}$ no están rindiendo, tenemos que bajar el nivel (Docente $1^{\circ}$ año medio).

Yo tengo que ser más profundo con el $2^{\circ} \mathrm{A}$ donde por sus notas más del $80 \%$ va a ir al HC donde el norte es la PSU. Lo tengo que hacer, y me agrada hacerlo, más encima. Pero en los otros cursos (...), por ejemplo, con Matemáticas tengo que hacer una adaptación, ya que la mayoría por sus notas se va a las especialidades de la TP, y un futuro contador o administrador tiene un perfil distinto a un futuro alumno que, va a ir a la universidad, ¿no es cierto? (Docente $2^{\circ}$ año medio).

Al etiquetarse a los estudiantes mediante la práctica del tracking, la explicación del éxito o fracaso escolar se construye en función de las expectativas que previamente los docentes han construido en torno a sus alumnos. Esto porque la evaluación final del curso y la de los propios sujetos escolares, al menos en parte, es una realización donde se ponen en juego los juicios y prejuicios construidos inicialmente y que se verifican en la forma de una profecía autocumplida (Coulon, 1995). Pero no solo los estudiantes son juzgados en función de su curso de pertenencia, sino también los apoderados. Los de las primeras secciones (A y B) son identificados como responsables y preocupados de la educación de sus hijos. En cambio, los de las letras siguientes, y muy particularmente aquellos cuyos hijos están en las últimas secciones $(F, G)$, son catalogados como ausentes y poco preocupados, y cuando están presentes, por lo general, asumirían conductas delegativas del tipo: "Profesora, hágase usted cargo porque yo no puedo", según manifestó uno de los docentes de estos cursos.

Por otra parte, en coherencia con la literatura crítica acerca de la práctica del tracking (Oakes, 1985), varios de los jóvenes entrevistados señalaron que su experiencia escolar está marcada por este proceso de segmentación y diferenciación al interior del establecimiento. Esto, 
porque el ordenamiento por calificaciones tendría una circularidad viciosa en la composición de los distintos cursos por nivel, al incluir como se ha visto la existencia de cursos modelo y cursos signados como de malos rendimientos y, por lo mismo, con mayor presencia de problemas conductuales. La experiencia escolar disímil según la letra de curso, y el predominio de actitudes personales que se vuelven funcionales a la división organizativa, fueron temas reiterativos que emergieron en las conversaciones con los estudiantes. Así lo sintetiza el siguiente relato de un estudiante que logró el cambio del grupo curso en su respectivo nivel:

Yo cuando estaba en el $1^{\circ} \mathrm{E}$, la mitad del curso estaba repitiendo y éramos como 30 y tres teníamos promedio arriba de 5,5 en ese curso y a los tres nos cambiaron; a los otros los echaron o repitieron (...). Yo no me dejaba influenciar por ellos, pero igual era incómodo, porque de repente tenía las ganas de escribir o de aprender algo y los chiquillos no, se ponían a hablar y me interrumpían mucho (...) en algunas materias no podíamos avanzar ya que quedaban dudas, pero no eran dudas de uno o dos, eran dudas de casi todo el curso y ahí teníamos que devolvernos; por eso digo que el curso E es más retrasado que el A o el B. Pero siento que después, cuando llegué al A, seguí normal solamente que me exigían más y ahí todos querían estudiar. Entonces me sentí mejor, porque así podía aprender más (Estudiante HC).

\subsection{El procedimiento de postulación a especialidades en el} ciclo de formación diferenciada

En el ciclo de formación diferenciada (grados 11 y 12), la conformación de grupos curso según rendimiento académico previo se mantiene, traslapándose con la elección por tipo de educación. Se trata de una práctica de tracking que adquiere el carácter de oficial, en la media en que la asociación entre los niveles académicos de los estudiantes y las opciones de formación diferenciada ofertadas por el establecimiento se alcanza mediante procedimientos que son formales y públicamente conocidos por los actores escolares (Lucas $\&$ Berends, 2002). En efecto, en el informativo de orientación que reciben los padres y apoderados al inicio del año escolar, y 
que describe el proceso de postulación a la modalidad HC y a las distintas especialidades TP, se pide a los estudiantes que se presenten a este proceso con una nota que permita proyectarse a los estudios superiores, un 5,8 para HC y 5,5 para las especialidades TP. El alumno de $2^{\circ}$ año medio que obtenga el promedio exigido al 31 de agosto del año en curso, queda inmediatamente seleccionado, previa firma del apoderado de un documento que asegure dicha elección. Los alumnos no seleccionados, ya sea por nota o informe de conducta, quedan en lista de espera hasta que el Departamento de Orientación o la Inspectoría General determinen si el alumno queda en alguna especialidad TP o en la HC con cupos disponibles.

Por su parte, el discurso de los actores educativos recalca que, en el marco de las restricciones institucionales existentes, la decisión final de incorporación a una u otra modalidad recae en los estudiantes y sus familias. Sin embargo, se hace evidente la construcción de un sentido común, que establece un principio natural de inclinación de los mejores estudiantes (o los que tienen mejores calificaciones escolares) hacia la modalidad HC, ya que este sería el canal natural para el desarrollo de una trayectoria destinada a la continuación de estudios superiores. Como se evidencia en la siguiente cita del orientador del establecimiento, la naturalización de la conducta también es aplicable a quienes optan por la TP, lo que le otorga una racionalidad previa en la elección de esta modalidad formativa:

Los alumnos que vienen con buenas notas siempre vienen con la expectativa de irse al HC, y los que quieren TP tienen claro a lo que vienen, a Contabilidad o Administración. Pero el sentido de superación y el incentivo a sacarse buenas notas, siempre está en los que apuntan a HC y luchan para ello. Así que los mejores cursos en cuanto a nota que logran un 5,8 hacia arriba están allí y no se hacen ningún problema porque ellos están en lo que quieren. Los casos complicados son aquellos que tienen notas muy bajas y a ellos los vamos dejando en lista de espera (Orientador).

Directivos y docentes del establecimiento justifican estas exigencias aduciendo las características propias del sistema de acceso a las universidades chilenas, donde la Prueba de Selección 
Universitaria (PSU) y el promedio de notas de la enseñanza media se constituyen en la puerta de ingreso a las instituciones universitarias (o por lo menos, a las de mayor prestigio). El determinismo en la relación entre calificaciones escolares, modalidad de estudios de enseñanza media y continuidad de estudios superiores, se refleja en las siguientes citas:

Queremos que nuestro alumno que va a HC, es decir, apuntando a la universidad, realmente quede en la universidad, porque un alumno que tiene un promedio 4,5 en $1^{\circ}$ y en $2^{\circ}$ año medio, no va a quedar en la universidad. Sería engañarlo si nosotros lo admitimos en HC cuando su promedio acumulado en esos cursos no da más que para un puntaje de 300 puntos en la PSU (...). Nosotros tratamos en HC de ser realistas con aquellos que tienen buenas notas, para encaminarles a la universidad. Los que tienen muy malas notas... difícil (Director establecimiento).

Existen estudiantes que quieren $\mathrm{HC}$ y tienen menos de un 5,8, entonces su misión es subir su promedio de notas de aquí al otro semestre o si no es algo irreal, se están mintiendo a sí mismos. Esto es lo que yo les digo: no puedes tú decirme que quieres seguir HC para después estudiar Ingeniería, si no te estás sacando la mugre en el liceo, eso es una tontera (Profesor jefe de $2^{\circ}$ año medio).

Pese a estas declaraciones y al procedimiento formal de postulación a especialidades vigente en el establecimiento (plasmado en el informativo de orientación), el discurso institucional es ambiguo cuando se pregunta directamente respecto de cómo se constituyen los grupos curso en el paso de la formación general a la formación diferenciada:

Aquí en verdad el alumno elige... verdaderamente elige... nosotros ponemos ciertas trabas en dos sentidos: la primera son las notas, algo de trabas se le coloca al alumno. Pero también hay una opinión del profesor que de repente puede venir a cuestionar la vocación de los alumnos (...). Entonces no son solo las notas... es más que todo el interés del alumno... luego las notas, luego la opinión del profesor jefe... el profesor, etc. (Director establecimiento). 
Se trata, entonces, de una elección con restricciones, donde los intereses o preferencias de los estudiantes quedan limitados. Primero por una definición institucional que otorga una mayor valorización a una de las modalidades formativas por sobre la otra, en la media en que los requisitos de calificaciones son dispares entre ambas (5,8 para HC y 5,5 para TP). Segundo, porque las elecciones vocacionales, también se filtran por el juicio que los docentes se forman de los estudiantes y que se transmite a través de sus recomendaciones, particularmente cuando a estos "les falta poquito para alcanzar la nota”. Según relató el orientador del establecimiento, este se reuniría durante el proceso de postulación a especialidades con los profesores jefes de $2^{\circ}$ año medio para conversar respecto del perfil de cada estudiante y sus antecedentes conductuales; es decir para saber "cómo es el alumno". Si tiene las habilidades desarrolladas para entrar a HC y "si es un estudiante de esfuerzo, le damos la pasada", manifestó este profesional.

Los testimonios de los estudiantes del establecimiento ratifican el papel decisivo que tienen las calificaciones escolares en sus elecciones educacionales. Además, el hecho de que las autoridades del liceo decidan por ellos cuando no quedan en la opción deseada, sería una realidad naturalizada. Particularmente, en el caso de los estudiantes que son asignados a las especialidades TP, el mecanismo de elección condicionada evidencia situaciones de resignación pasiva o desajuste vocacional, que no necesariamente resultan bien canalizados en beneficio de sus intereses y posibilidades futuras. En una entrevista colectiva con estudiantes de especialidades TP, esta realidad fue evidente, tal como se infiere de los testimonios que se presentan a continuación:

Yo me frustré cuando no quedé en HC; pero mi mamá conversó el tema conmigo y me dijo que con una especialidad TP yo podía trabajar primero y estudiar después, y si después no quería, no era necesario ir a la universidad (Estudiante TP).

Yo quiero estudiar Kinesiología al terminar el colegio y ese es el tema, Administración no sirve para eso (...). Muchos aquí queremos estudiar algo que tiene que ver HC, y la preparación 
que nos dan en las especialidades TP hace que tengamos que pensar en entrar a un preuniversitario y tener que pasar un año completo allí antes de dar la PSU (Estudiante TP).

A diferencia del grupo TP, los estudiantes de la modalidad HC expresan, con mayor recurrencia, un discurso alineado con su modalidad y funcional a un proyecto de continuidad de estudios superiores una vez finalizada la enseñanza media. El énfasis dado al esfuerzo personal y a la perspectiva de apoyo familiar en el proyecto de futuro, se visibiliza en el testimonio de esta estudiante:

En mi caso, mis papás siempre me inculcaron que todo lo que yo haga lo hiciera por mí, y yo siempre lo he tenido claro. De hecho, desde chica he sabido lo que quiero y he trabajado por eso y todo: mi elección de lo que quiero estudiar, la elección del HC, mis notas y todo es por mí. Aparte que tengo tres hermanos antes que yo y los tres con experiencias malas estudiando, de hecho, por eso es como que los vi a ellos y yo dije no, yo tengo mi meta y esa meta la quiero cumplir (Estudiante HC).

3.5. El rol de la orientación: ¿apoyo vocacional o canalización institucional?

El liceo Almirante Barroso ha experimentado distintas formas de apoyar a sus estudiantes en sus elecciones educacionales según lo señalado por sus autoridades. Hace algunos años, el énfasis se puso en el desarrollo de actividades de inducción a través de charlas informativas a cargo de los docentes del ciclo de formación diferenciada que se realizaban durante $1^{\circ}$ y $2^{\circ}$ año medio. Estas charlas resultaban particularmente relevantes en el caso de las especialidades TP, debido al desconocimiento acerca de las características de esta oferta formativa por parte de los estudiantes. Sin embargo, con el paso del tiempo, se concluyó que el despliegue de estas actividades con la participación de los docentes de especialidad no era necesario y que bastaba una inducción por parte del orientador en $2^{\circ}$ año medio. La justificación de este cambio es expresada en los siguientes términos por el director del establecimiento: 
El cambio lo hicimos porque vimos que lo que se necesita no es una cuestión de materia, por lo que las charlas las podía hacer una misma persona para todas las especialidades (...), lo que vimos es que los chiquillos se impregnan solos, por el hecho de estar en un colegio y compartir, convivir con compañeros que están en Administración, en Contabilidad, ellos se van formando la idea de cómo es el perfil de la especialidad (Director establecimiento).

En otras palabras, desde la perspectiva institucional predominante, la opción por la modalidad HC o por una especialidad TP correspondería a un proceso de elección individual, a partir de las propias capacidades de organización de información que manejarían los estudiantes. Es importante recordar que se trata de jóvenes que en promedio tienen una edad de 15 a 16 años y cuyo ingreso al establecimiento, en la gran mayoría de los casos, se debe a una decisión de sus padres u otro adulto significativo de su entorno familiar.

Además, según lo señalado por el orientador, en $2^{\circ}$ año medio ya existiría un alto porcentaje de estudiantes que tiene tomada su decisión respecto de la modalidad de estudios que desean seguir. En ese escenario, la actividad de orientación vocacional tiende a estar centrada en explicar las posibilidades de cupo que existen para los estudiantes en función de su situación escolar previa, y en disminuir el número de estudiantes indecisos:

Hay más o menos un 70\% que ya tiene su decisión tomada y que ya tiene o está catalogado dentro de lo que quiere, pero hay otro 30\% que no. Aquellos que están indecisos todavía, deben conversar con sus papás y decidir, porque a mí no me sirve un alumno que me diga yo quiero Contabilidad y de repente se cambia a Administración, porque ese es un problema para nosotros (...). Entonces yo les hago firmar un documento que tiene la firma del apoderado y del alumno que dice la decisión que yo tomé fue la mejor y nos hacemos responsables de eso. Al final siempre llegan algunos indecisos, pero son los menos, gracias a eso (Orientador). 
Pero, ¿cómo es específicamente el proceso de postulación a las especialidades en el Liceo Almirante Barroso? Según explicó el mismo orientador en una de las visitas realizadas al establecimiento, la postulación de los estudiantes se formaliza al finalizar el primer semestre de $2^{\circ}$ año medio, a través del llenado de un documento donde tienen que especificar sus dos primeras opciones para el año siguiente. En una etapa previa, desde el Departamento de Orientación se entrega información respecto de las características de cada especialidad TP, pero como se señaló, sin una mayor profundización en aspectos relacionados con el modelo formativo, perfil de egreso y perspectivas educativo-laborales luego del egreso de la enseñanza media. En la instancia de llenado del formulario de postulación se informa a los estudiantes acerca de su promedio de notas acumulado hasta el primer semestre y, si fuera el caso, los puntos que deben subir en lo que resta del año escolar para cumplir con el requisito de nota mínima asociada a su elección. Este proceso está a cargo del profesor jefe de cada curso y se realiza en la primera semana de agosto durante horario de clases.

Para observar in situ este proceso, en el marco de este estudio acompañamos a una profesora jefa de $2^{\circ}$ año medio, quien tenía pendiente realizar la consulta a 12 estudiantes que habían estado ausentes en el proceso inicial donde realizó la indagación al resto de sus compañeros. Describimos a continuación el resultado del trabajo de observación realizado en torno a esta experiencia:

En el tercer piso del primer edificio, según nos indicó la secretaria del liceo, se encontraba la sala del $2^{\circ}$ año medio D. En su puerta nos esperaba la profesora jefe, mientras que en su interior cerca de 40 estudiantes terminaban de rendir una prueba bajo la supervisión de dos estudiantes de Pedagogía que estaban en práctica. Muchos de los estudiantes hablaban en voz alta, otros estaban fuera de sus pupitres caminando con la hoja de prueba en sus manos. Nuestra guía pidió silencio y concluir con la entrega de la prueba inmediatamente. Sin más esfuerzo por lograr el orden, indicó a los estudiantes que concluiría el llenado de la hoja de postulación para los cursos de $3^{\circ}$ año medio, a quienes habían faltado la clase anterior; para ello, colocó dos pupitres 
próximos a la pizarra. En uno de estos se ubicó ella y en el otro lo ocuparía el estudiante consultado.

Profesora: Catalina Martínez usted faltó la clase pasada, ¿puede indicarme a qué especialidades quiere postular?

Catalina: ¿Qué especialidades son?

Profesora: Administración, Contabilidad, Secretariado y HC.

Catalina: ¿Qué entra en Administración?

Profesora: ¿Cómo?, ¿el orientador no les describió el perfil de esta especialidad?

Catalina: No, solo lo hizo para Contabilidad y Secretariado, la próxima semana recién toca Administración.

Profesora: ¿Pero a qué va a postular?

Catalina: Administración y Secretariado.

La profesora describió rápidamente el perfil de la especialidad de Administración, pero sin duda su mayor preocupación era que la estudiante firmara la hoja de postulación. Continuó el próximo estudiante, quien con paso desganado y entre medio del bullicio que aumentaba de volumen, se dirigió al frente de la sala.

Profesora: ¿A qué va a postular?

Felipe: A Contabilidad.

Profesora: ¿Vas a postular a Contabilidad, pero con esa nota? Te alcanza para Administración.

Felipe: Entonces Administración, pero ¿para qué otra cosa más me alcanza?

Profesora: Para eso, y solo si se abren cupos, para Contabilidad.

La profesora nos comenta que al estudiante "no le queda otra", pero que este ha manifestado que se va a retirar del liceo al año siguiente, porque no le gusta que lo manden. El estudiante alcanza a escuchar esta última frase y nos dice que no es por eso que se cambiará a otro liceo.

Profesora: Tú Ramón, ¿a qué vas a postular? 
Ramón: Estoy indeciso, lo que pasa es que para ser profesor tengo que estudiar HC...

Profesora: Pero usted tiene que subir las notas; 5,2 no le alcanza.

Ramón: Pero quiero ser profesor de Música... entonces sería Contabilidad, aunque después igual estudiaría para ser profesor de Música.

Entonces la profesora registra dentro de sus opciones Contabilidad como primera opción y HC como segunda. Continúa con Ivana quien dice firmemente que va a postular a Administración y Secretariado. El trámite concluye con la firma del formulario en menos de un minuto.

Profesora: Francisco es su turno, ¿a qué va a postular?

Francisco: A HC.

Profesora: ¿Solo a eso?, pero tiene dos opciones. No le va a alcanzar con el 4,3 que tiene.

Francisco: Si lo sé, pero igual quiero HC.

Profesora: ¿Pero a qué más?

Francisco: Ya... póngame Administración.

Preguntamos directamente a Francisco por qué quería estudiar en HC; nos señaló que quería estudiar Ingeniería en Minas. Parecía razonable su opción si aspiraba a esa carrera, dado que en el liceo solo se ofrecían especialidades TP del sector de Administración y Comercio. Al final la profesora quien escuchó atentamente nuestro diálogo recalcó que "todo va acompañado de notas", que Francisco tenía que rendir el doble el segundo semestre si quería llegar ahí, y que había llamado a su papá para conversar al respecto, pero que su papá "no estaba ni ahí". Francisco asintió con su cabeza a este último comentario.

La profesora intenta hacer callar al curso, "corten la tontera" dice, seguidamente recita nuevamente las opciones de postulación a una nueva alumna que tiene al frente, Javiera.

Profesora: Ya, ¿cuáles son sus opciones Javiera? 
Javiera: HC y Contabilidad.

Profesora: Pero tienes que subir tus notas y para subir una décima el promedio que tienes en seis materias.

Javiera: Ah, pero solo me gusta HC, las otras especialidades no.

La profesora nos comenta que la mamá de la alumna le manifestó que si no quedaba en HC la cambiaba de liceo, "así que lo más probable es que la alumna se vaya al próximo año". Finalmente, después de cuatro estudiantes que sostienen un diálogo corto con la profesora jefe para indicar sus opciones y firmar rápidamente su hoja de postulación, es el turno de Carolina.

Profesora: ¿A qué vas a postular?

Carolina: A Secretariado, porque me gusta estar en una oficina, también Administración, pero no Contabilidad, porque quiero estudiar Gastronomía.

La respuesta de la estudiante deja pensando a la profesora. Nosotros intervenimos diciéndole que si quiere estudiar Gastronomía al salir del liceo podría estudiar Administración, y más tarde administrar su propio restaurant. Nuestra sugerencia le parece una buena idea a Carolina, quien dice que su primera y segunda opción es Administración.

Concluye la profesora en menos de una hora la ronda de consulta a los estudiantes. Antes de abandonar la sala recorremos los pupitres y conversamos con algunos estudiantes que ya estaban de recreo, pero en horario de clases. En medio del desorden divisamos a un estudiante, distinto al resto. Guardaba silencio y con ayuda de sus audífonos y un chaleco azul de cuello alto que llegaba hasta su nariz intentaba aislarse, mientras que el resto del curso vociferaba. Nos contó que era nuevo en el liceo y que había entrado ahí porque quería seguir la especialidad de Administración. Él quería, después de salir de $4^{\circ}$ medio, seguir estudiando algo relacionado, quizás en un instituto o en la universidad, pero que no podía hacerlo inmediatamente; antes tenía que trabajar, y para eso le servía la especialidad, para tener un título. 


\section{Discusión final}

Este trabajo de indagación de corte etnográfico permitió abordar una temática que ha sido débilmente tratada por la investigación socioeducativa en las últimas décadas: la elección entre educación HC y TP. Esta elección suele ser naturalizada y poco cuestionada, admitiéndose de manera simple y reductiva que la modalidad TP es para los estudiantes de menor nivel socioeconómico, mientras que para el resto, con mayores posibilidades e interés de continuar estudios superiores, lo es la modalidad HC. Como tendencia general, esta asociación entre perfil de estudiantes, elección de modalidad formativa y proyecciones a futuro se mantiene, pese a la ampliación de las aspiraciones de continuidad de estudio de las nuevas generaciones y de masificación de las alternativas de educación superior. El modelo polivalente, al postergar una decisión curricular temprana, tiene el potencial de hacer que esta se tome en función de una mayor consideración de los intereses y motivaciones de los propios estudiantes equilibrando ambas modalidades para la construcción de proyectos educativos igualmente valorizados socialmente. ¿Qué evidencia el estudio de caso aquí presentado?

El estudio de caso presentado advierte que cuando las calificaciones escolares condicionan las elecciones educacionales al interior de los establecimientos polivalentes, las potencialidades de este modelo se reducen drásticamente. Esto, porque al canalizar a los estudiantes mejor evaluados hacia la modalidad HC, asignando al resto a las especialidades TP con independencia de sus intereses y aspiraciones a futuro, emergen nítidamente las características comunes y predecibles de la práctica del tracking temprano que atentan contra la equidad educativa. Se produce un ajuste de expectativas de parte de los docentes que repercute en la instrucción y en los contenidos impartidos entre estudiantes de ambas modalidades. Se constituyen grupos no comparables, sino más bien jerarquizados donde la HC se ubica en el nivel más alto y privilegiado, seguida por las distintas especialidades TP que se ordenan en función de la demanda vigente. Esta jerarquización, que deja de manifiesto la reproducción de un modelo cultural fuertemente arraigado en la sociedad chilena que valora como inferior toda alternativa educativa 
que no sea universitaria, produce a la vez una circularidad viciosa que estigmatiza a los estudiantes según su curso de pertenencia, acentuado problemas de rendimiento académico y conductuales entre quienes no alcanzaron la calificación que les permitía acceder a la HC.

Directivos y docentes justifican y defienden esta lógica de gestión de la diversidad estudiantil del establecimiento que condiciona sus elecciones educacionales a las calificaciones escolares. Desde su perspectiva, si se abre la puerta de la HC a todos los estudiantes, sería contraproducente ya que resulta más adecuado que quienes presentan dificultades escolares tempranas, continúen estudios en la TP, debido a su "menor exigencia académica" y por tratarse de una alternativa temprana de ingreso al mercado laboral. Luego, no se observa un cuestionamiento a la segmentación que la práctica del tracking genera en el establecimiento, así como tampoco al condicionamiento de las trayectorias futuras de sus estudiantes por sobre las orientaciones vocacionales que estos puedan construir en su paso por la enseñanza media. Además, se evidencia cómo la institucionalización de la selectividad académica al interior de una institución escolar, normaliza el impedimento del logro de dos objetivos altamente valorados en la educación: ayudar a los estudiantes a alcanzar altos niveles de excelencia académica y proveer a todos los estudiantes las mismas oportunidades de alcanzar dichos niveles (Oakes, 1985).

En suma, el análisis en profundidad de una experiencia en particular, contrastando lo que los actores escolares dicen y hacen, permitió identificar aspectos socioculturales presentes en el sistema educativo que son claves para la discusión acerca de la diferenciación curricular y el agrupamiento por habilidades académicas y no académicas entre estudiantes. Este debate es aún incipiente en Chile y requiere una mayor consideración, no solo por la relevancia de la educación TP en el sistema educativo, sino también por el efecto de equidad social que esta realidad implica. Los procedimientos de canalización de intereses y motivaciones vocacionales de los estudiantes constituyen un tema urgente que debe motivar una mayor visibilidad y discusión, no solo en la comunidad investigativa, sino también entre los gestores y autoridades educativas. 


\section{Referencias}

Ansalone, G. (2009). Tracking, schooling and the equality of educational opportunity. Race, Gender E Class, 16(3-4), 174-184.

Ainsworth, J. \& Roscigno, V. (2005). Stratification, school-work linkages and vocational education. Social Forces, 84(1), 257-84. https://doi. org/10.1353/sof.2005.0087

Bracey, G. W. (2003). Tracking, by accident and by design. Phi Delta Kappan, 85(4), 332-333. https://doi.org/10.1177/003172170308500418

Bobenrieth, E. \& Cáceres, C. (1994). Un modelo de selección de liceos de enseñanza media. Cuadernos de Economía, 31(92), 27-44.

Cariola, L. (2003). Estructura y currículum de la educación media. Cambios y reformas, 1980-2000. En L. Cariola, C. Bellei e I. Núñez, I. (Eds.), Veinte años de políticas de educación media en Chile (pp. 27-165). Paris: Unesco, IIPE.

Collins, C. A., \& Gan, L. (2013). Does Sorting Students Improve Scores? An Analysis of Class Composition. (NBER Working Paper No. 18848. National Bureau of Economic Research). https://doi.org/10.3386/ w18848

Coulon, A. (1995). Etnometodología y educación. Barcelona: Paidós

Díaz de Rada, A. (2008). ¿Qué obstáculos encuentra la etnografía cuando se practica en las instituciones escolares? En M. Jociles y A. Franzé (Eds.), ¿Es la escuela el problema?: perspectivas socio-antropológicas de etnografía y educación (pp. 19-52). Barcelona: Ed. Trotta.

Farías, M. (2014). School choice and inequality in educational decisions. Multidisciplinary Journal of Educational Research, 4(1), 1-34. https://doi. org/10.1080/15582159.2012.673854

Gamoran, A. (1992). The variable effects of high school tracking. American Sociological Review, 57(6), 812-828. https://doi.org/10.2307/2096125

Hallinan, M. (1994). School differences in tracking effects on achievement. Social Forces 72(3), 799-820. https://doi.org/10.2307/2579781

Hammersley, M. y Atkinson, P. (1994). Etnografía. Barcelona: Paidós.

Lucas S. \& Berends, M. (2002). Sociodemographic, diversity, correlated achievement, and de facto tracking. Sociology of Education, 75(4). 328348. https://doi.org/10.2307/3090282

Loveless, T. (1999). The tracking wars: State reform meets school policy. Washington D.C.: Brookings Institution Press. 
Oakes, J. (1985). Keeping track: How schools structure inequality (2nd ed.). New Heaven, London: Yale University Press.

Oakes, J., \& Guiton, G. (1995). Matchmaking: The Dynamics of High School Tracking Decisions. American Educational Research Journal, 32(1), 3-33. https://doi.org/10.3102/00028312032001003

Raczynski, D. y Hernández, M. (2011). Elección de colegio, imágenes, valoraciones y conductas de las familias y segregación social escolar. Santiago de Chile: Asesorías para el Desarrollo.

Ruiz, C. (2010). De la República al mercado. Ideas educacionales y política en Chile. Santiago de Chile: LOM Ediciones.

Shavit, Y. (1984). Tracking and ethnicity in Israeli secondary education. American Sociological Review, 49(2), 210-220. https://doi. org/10.2307/2095571

Sevilla, M. P. (2016). Diferenciación curricular y estratificación escolar: El impacto de la polivalencia en la educación media chilena. Santiago de Chile: Universidad Diego Portales-Universidad Alberto Hurtado.

Sevilla, M. P. y Sepúlveda, L. (2016). Selección en liceos polivalentes. Análisis de los mecanismos de adscripción de estudiantes a la modalidad científico-humanista o técnico-profesional. Revista Estudios Política Educativa, 3, 74-105.

Treviño, E., Valenzuela, J. P., Villalobos, C., Béjares, C., Wyman, I., y Allende, C. (2018). Agrupamiento por habilidad académica en el sistema escolar. Nueva evidencia para comprender las desigualdades del sistema educativo chileno. Revista Mexicana de Investigación Educativa, 23(76), 45-71.

Wilcox, K (1988). Ethnography as a methodology and its applications to the study of schooling: A review. En G. Spindler (Ed.), Doing the ethnography of schooling: Educational anthropology in action (pp. 456488). Illinois: Waveland Press.

Wolcott, H. (2006). Sobre la intención etnográfica. En H. Velasco, F. J. García Castaño, y Á. Díaz de Rada Brun (Eds.), Lecturas de antropología para educadores (pp. 127-144). Barcelona: Editoral Trotta.

Recibido: 31/08/2018

Aceptado: 18/04/2019 